\title{
Proportion and Factors of Postpartum Depression Among Cesarean Section Versus Vaginal Deliveries: Institutional Based Cross-Sectional Study
}

\author{
Mezgebu Mihret Kefale ${ }^{1}$, Selamawit Lake Fenta ${ }^{1}$, Fentahun Yenealem Beyene ${ }^{1}$, \\ Natnael Atnafu Gebeyehu, * \\ ${ }^{1}$ Department of Midwifery, College of Health Science and Medicine, Bahirdar University, Bahirdar, Ethiopia \\ ${ }^{2}$ Department of Midwifery, College of Health Science and Medicine, Wolaita Sodo University, Wolaita Sodo, Ethiopia \\ Email address: \\ mezgebmihret4@gmail.com (M. M. Kefale), selamawitfenta@yahoo.com (S. L. Fenta), yenefenta84@gmail.com (F. Y. Beyene), \\ natnaelatnafu89@gmail.com (N. A. Gebeyehu) \\ *Corresponding author
}

\section{To cite this article:}

Mezgebu Mihret Kefale, Selamawit Lake Fenta, Fentahun Yenealem Beyene, Natnael Atnafu Gebeyehu. Proportion and Factors of Postpartum Depression Among Cesarean Section Versus Vaginal Deliveries: Institutional Based Cross-Sectional Study. European Journal of Biophysics. Vol. 8, No. 1, 2020, pp. 1-9. doi: 10.11648/j.ejb.20200801.11

Received: March 27, 2020; Accepted: April 23, 2020; Published: June 4, 2020

\begin{abstract}
Background: postpartum depression is a severe health problem which affects both developing and developed countries. It is one of the diseases which affect women after the delivery of their baby and difficult to manage because of the presence of postpartum blues. Objective: To assess the proportion and factors of postpartum depression following normal vaginal deliveries and cesarean section among postnatal women at Finoteselam Hospital, April 05, 2018-May 20, 2018. Result: The proportion of postpartum depression among postpartum women was $13 \%$ of which $9.1 \%$ and $3.9 \%$ for vaginal and cesarean delivery respectively. In this study; previous history of postpartum depression [AOR=5.498 (1.843-16.405)], no domestic violence $[\mathrm{AOR}=0.250(0.065-0.956)]$, women who faced negative life event [AOR=17.322 (4.753-63.135)], previous history of two abortion [AOR=0.160 (0.034-0.746). Previous history of mental illness, [AOR=.187 (0.053-0.659)], being at the level of secondary education $[\mathrm{AOR}=8.818(1.596-48.716)]$ and husband support during pregnancy [AOR=.048 $(.014-.164)]$ had an association with postpartum depression. All the individual Edinburgh postnatal depression scale score mean values were higher for the cesarean group which was 6.97 when compared to the vaginal delivery group was 5.865. Conclusion: Prevalence of postnatal depression was comparably high in vaginal deliveries compared to cesarean sections. By revealing the prevalence and factors that determine postpartum depression, this study recommended interventions like Integration of mental health service with existing maternal health care and health institutions to prevent Postpartum depression at Finoteselam Hospital.
\end{abstract}

Keywords: Postpartum Depression, Proportion, Risk Factors

\section{Introduction}

Postpartum depression is defined as groups of clinical as well as depressive symptoms and syndromes which can occur in a women's postpartum period. It is categorized into a major and minor depression that begins within 4 weeks of the Postnatal period [1].

Worldwide, about $10 \%$ of pregnant women and $13 \%$ of who just gave birth are affected by mental health problems. In developing countries, it is higher $15.5 \%$ through pregnancy and $19.8 \%$ after child birth [6]. Based on the
Ethiopian national mental health strategy done by the Federal Democratic Republic of Ethiopia Ministry of Health mental illness is the leading non-communicable disorder in terms of burden [2].

Postpartum depression affects more than one in ten women and vulnerable for mother, child, and family. Combining mental Health care into maternal health is the main mechanism to effective care and reducing "poor management 'in low- and middle-income countries [3]. The diagnosis is difficult because of the variability in clinical presentation. Therefore, postpartum depression is often confused with 
baby blues or postpartum psychosis. The transition to new motherhood, including postpartum depression, has been associated with emotional distress up to $30 \%$ of women $[4,5]$

Women who experience depression during pregnancy were found to have a five times higher risk of developing postpartum depression and women with anxiety during pregnancy were found to Have a three times higher risk [6]. Postnatal depression is an important public health concern both in the developing and developed world that increases maternal morbidity and mortality. The proportion of postpartum depression is increasing in Ethiopia, yet the determinant of this problem has not been identified clearly [7].

Some study shows that women with various risk factors related to health, environment and social factor will have a higher chance of developing a postpartum depression [8]. Other research explains the suspected involvement of other psychosocial risk factors, Such as poor communication with the husband [9], having other children in the home, low educational level, being an adolescent mother [10], previous prenatal depression, previous depression, lack of social support, life stress, childcare stress, severe maternity blues, marital dissatisfaction, and prenatal anxiety. The aim of the study is to find out the unsearched and untouched prevalence and associated factor of postpartum depression among postpartum women $[1,6,11]$.

Determining the proportion and factor affecting postpartum depression among postnatal women is very crucial in designing and implementing interventions that could be tailored to women needs, thereby contributing to the attainment of the Sustainable Development Goal Three target 3.1 reductions in maternal mortality. Therefore, this study is believed to establish an insight about current postpartum depression and its determinants that can be used as an input to influence the national policymakers, program formulators and program implementers to take an appropriate intervention $[2,7]$.

\section{Method and Materials}

\subsection{Study Area}

The study was conducted at Finoteselam Hospital, Finoteselam city, Northwest Ethiopia. It is located approximately $387 \mathrm{~km}$ far from Addis Ababa, the capital city of Ethiopia. According to the data obtained from the administrative office of the city, there are a total of 68720 populations of which only 38674 are females of reproductive age groups. The hospital has a total of 350 health professionals. An average number of delivery was 13 women per day and 45 postpartum women visit the postnatal clinic monthly.

\subsection{Study Design and Period}

An Institutional based cross-sectional study was conducted from April 05 to May 20, 2018.

\subsubsection{Source Population}

All postpartum women attended the postnatal clinic at Finoteselam Hospital.

\subsubsection{Study Population}

All selected postpartum women who were available at Finoteselam Hospital within the study period.

\subsubsection{Inclusion Criteria}

All women who gave birth and came for postnatal care service within 6 weeks after delivery at Finoteselam Hospital during the study period were included.

\subsubsection{Exclusion Criteria}

All postpartum women who had serious physical and mental illness were excluded from the study. All postpartum women who developed PPD but treatment were given at the time of data collection were also excluded in this study.

\subsubsection{Dependent Variable}

Postpartum depression

\subsubsection{Independent Variables}

1. Socio-demographic characteristics (age, educational status, economic status, marital Status and employment)

2. Social support (Poor husband support, domestic violence, Childbirth without the Presence of any relatives, unsatisfactory relationship with the mother-inlaw, unsatisfactory Relationship in marriage).

3. Substance use (substance use during pregnancy).

4. Obstetrics factors (parity, unplanned pregnancy, losing or hospitalizing a baby, mode of delivery, pregnancy complication or illness, Stressful life event during pregnancy and undesired fetal sex).

5. Previous psychiatric history (history of depression and family history of psychiatric Problems).

\subsection{Operational and Term Definitions}

1. Postpartum depression; according to Edinburgh postnatal depression scale (EPDS) Questions 1, 2, \& 4 are scored $0,1,2$ and 3 with the first choice scored as 0 and the last choice scored as 3. Questions 3, 5-10 are reversely scored, with the first choice. After adding up all the scores, those women who scored $\geq 13$ were concluded to have postpartum depression.

2. Social support: the perception and actuality that one is cared for, has assistance available from other people.

3. Complication: Illness during and after pregnancy

4. Negative event: bad outcome in pregnancy life.

\subsection{Sample Size Determination}

The sample size was calculated using the formula for two population proportion with the following assumptions.

$$
\mathrm{n} 1=\frac{2 \sqrt{\mathrm{PQ}\left(1+\frac{1}{\lambda}\right)}+\mathrm{Z} \beta \sqrt{\mathrm{P} 1 \mathrm{q} 1+\frac{\mathrm{P} 2 \mathrm{q} 2}{\lambda}}}{\Delta^{2}}
$$




$$
\begin{gathered}
=\mathrm{n} 2=\mathrm{n} 1 \lambda \\
\mathrm{P}=(\mathrm{p} 1+\lambda \mathrm{p} 2) /(1+\lambda)
\end{gathered}
$$

$\mathrm{P} 1=$ the prevalence of PPD among vaginal deliveries of women who are $23.8 \%$ [12] Based on a study in Addis Ababa.

P2=the prevalence of PPD among cesarean deliveries women who was $15.3 \%$.

$$
\begin{gathered}
\mathrm{q}=1-\mathrm{p} \\
\mathrm{p} 1=0.238, \mathrm{p} 2=0.153, \mathrm{p}=(0.238+3 * 0.153) /(1+3)=0.174 \\
\mathrm{q} 1=0.772, \mathrm{q} 2=0.847, \Delta=0.238-0.153=0.085
\end{gathered}
$$

$\mathrm{Z} @ / 2=$ is the standard normal value at $95 \%$ confidence level $=1.96$

$Z \beta=$ The Z-score corresponding to Power $=0.84$

$$
\Delta=\mathrm{p} 1-\mathrm{p} 2
$$

$\mathrm{n} 1=70$ (caesarean section) $\mathrm{n} 2=210$ (vaginal delivery), then adding $10 \%$ of non-response rate for both of population. The required Sample size: $n 1=77$ (caesarean section) $n 2=231$ (vaginal delivery). The total final sample size was 308.

\subsection{Sampling Techniques and Procedures}

A systematic sampling procedure was applied to select the study participants. After taking a sample for three months an average number of populations from both delivery and postnatal clinic were 1260 of whom 630 women obtained delivery service at the hospital. Then it is dividing by sample size of 308 , i.e. $\mathrm{k}^{\mathrm{t}}=$ sampled population/sample size $=630 / 308=2$. So the first participant was selected by lottery method and others were selected by every other interval until the required sample obtained.

\subsection{Data Collection Instrument and Procedure}

Data was collected by a pretested interviewer-administered Structured questionnaires which were composed of sociodemographic variables, economic factors and obstetric history of pregnant women. The questionnaire was initially prepared in English and then translated into Amharic, the local language. One degree holder health officer and three psychiatric nurses participated as a supervisor and data collectors respectively trained at Finoteselam hospital for one day. Evaluation for depression was done through self-rating for depression using the Edinburgh Postnatal Depression Scale [25]. This evaluated how the mother had been feeling for the past seven days. Different scores were awarded based on the best response given by the mother. A cut off point/score of $\geq 13$ was used to determine whether the mother had depression or not.

\subsection{Data Quality Control and Assurance}

To assure data quality the instrument was translated to Amharic local language. A questionnaire has been pre-tested on 31 postnatal women from Debremarkos Hospitals and modifications were done accordingly. Training of supervisors and data collectors on the data collection, entering, coding, cleaning, and editing was done before the actual data collection.

\subsection{Data Processing and Analysis}

After data collection, each questionnaire was checked for completeness and consistency. Data were entered into Epi Info version- 7 software and exported to SPSS version-23 statistical software. Descriptive analysis was carried out by calculating the frequency, proportion, mean, standard deviation, 95\% confidence interval and frequencies of different variables using SPSS version-23. Finally, the result was presented with tables, graphs, and charts.

The association between the independent and outcome variables was first investigated using Bivariate logistic regression analysis and those candidate variables with $\mathrm{p}$ value $<0.2$ were moved to multivariable logistic regression analysis to identify risk factors for PPD.

\section{Result}

Socio-demographic characteristics

A total of 308 post-partum women participated in this study. All of the participants responded fully to all the questions. The majority of the participants were in the age group of 25-34 years which accounted for 51\% for both study groups of vaginal and Caesarean delivery with a mean age of $28.43 \pm 6.4$ years. Among the total respondents, $249(80.2 \%)$ were married, of which $62.7 \%$ was vaginal and $18.2 \%$ was cesarean deliveries.

More than half of the respondents $162(52.6 \%)$ attended formal education and most of the participants 59 (19.2\%) were at primary school by the level of educational status. The proportion of Illiterate clients in both the study groups were $(35.7 \%)$ for normal delivery and $(10.7 \%)$ for cesarean delivery. The majority of the respondents 180 (58.4\%) were from a rural area of residency. Orthodox Christianity was the dominant religion which was $87.3 \%$ among respondents. One hundred twenty-eight of respondents $(41.6 \%)$ did not know their specific income category for both vaginal and cesarean delivery (Table 1).

Table 1. Socio-demographic characteristics' of postpartum women at Finoteselam hospital, North West Ethiopia 2018 ( $n=308)$.

\begin{tabular}{lllll}
\hline Types of variables & Category & Frequency of VD $(\mathbf{n}=\mathbf{2 3 8})$ & Frequency CS $(\mathbf{n}=\mathbf{7 0})$ & Total $(\mathbf{n}=\mathbf{3 0 8})$ \\
\hline \multirow{3}{*}{ Age in years } & $15-24$ & 67 & 22 & $89(28.9 \%)$ \\
& $25-34$ & 126 & 31 & $157(51 \%)$ \\
Religion & $>35$ & 45 & 17 & $62(20.1 \%)$ \\
\hline
\end{tabular}




\begin{tabular}{|c|c|c|c|c|}
\hline Types of variables & Category & Frequency of VD $(n=238)$ & Frequency CS $(n=70)$ & Total $(n=308)$ \\
\hline \multirow{4}{*}{ Marital status } & Protestant & 6 & 1 & $7(2.3 \%)$ \\
\hline & Muslim & 20 & 12 & $32(10.4 \%)$ \\
\hline & Married & 193 & 56 & $49(80.8 \%)$ \\
\hline & Unmarried & 45 & 14 & $59(19.2 \%)$ \\
\hline \multirow{2}{*}{ Attende school } & Yes & 126 & 36 & $162(52.6 \%)$ \\
\hline & No & 112 & 34 & $146(47.4 \%)$ \\
\hline \multirow{4}{*}{ Highest level of education } & Primary school & 48 & 11 & $59(19.2 \%)$ \\
\hline & Secondary school & 31 & 15 & $46(14.9 \%)$ \\
\hline & Others & 49 & 11 & $60(19.5 \%)$ \\
\hline & Not educated & 110 & 33 & $143(46.4)$ \\
\hline \multirow{2}{*}{ Work at postpartum } & Yes & 132 & 38 & $170(55.2 \%)$ \\
\hline & No & 106 & 32 & $138(44.8 \%)$ \\
\hline \multirow{2}{*}{ Sex } & Male & 108 & 30 & $138(44.8 \%)$ \\
\hline & Female & 130 & 40 & $170(55.2 \%)$ \\
\hline \multirow{3}{*}{ Desired sex } & Wanted & 118 & 35 & $153(9.7 \%)$ \\
\hline & Unwanted & 50 & 14 & $61(20.8 \%)$ \\
\hline & I don't mind & 70 & 21 & $91(29.5 \%)$ \\
\hline \multirow{2}{*}{ Occupational status } & Employed & 234 & 70 & $304(98.7 \%)$ \\
\hline & Unemployed & 4 & 0 & $4(1.3 \%)$ \\
\hline \multirow{2}{*}{ Difficult with income } & Yes & 134 & 38 & $172(55.8 \%)$ \\
\hline & No & 104 & 32 & $136(44.2 \%)$ \\
\hline \multirow{6}{*}{ Monthly income } & $\leq 1650$ & 27 & 8 & $35(11.4 \%)$ \\
\hline & $1651-3145$ & 38 & 8 & $46(14.9 \%)$ \\
\hline & $3146-5195$ & 19 & 8 & $27(8.8 \%)$ \\
\hline & $>5196$ & 16 & 3 & $19(6.2 \%)$ \\
\hline & I don't know & 99 & 29 & $128(41.6 \%)$ \\
\hline & No income & 39 & 14 & $53(17.2 \%)$ \\
\hline
\end{tabular}

Obstetric and clinical characteristics

From the total respondents, only $77.3 \%$ and $22.7 \%$ were giving birth with vaginally and cesarean section respectively. Moreover, the sex of the last baby had a comparable sex distribution of $49.7 \%$ male and $50.3 \%$ female. In addition, regarding the desired sex of the last Baby 153 (49.7\%) respondents were with the desired sex of their infants in both groups $38.3 \%$ for vaginal delivery and 11.4 for cesarean delivery. Furthermore, $53.2 \%$ of VD and $15.3 \%$ of CS had no abortion history. One hundred thirty-eight (44.8\%) respondents giving birth to a male baby and one hundred seventy $(55.2 \%)$ were female.

One hundred eighty (58.4\%) of the participants claimed that they had used substance before Pregnancy and alcohols (local alcoholic beverage (Areke and Tela), Beer and Coffee) which accounted $47.1 \%$ of vaginal delivery and $9.7 \%$ of cesarean section for both groups than those who were abused during pregnancy was (15.5\%).

Personal and family history of depression among postpartum women

A total of $19.8 \%$ of participants had the previous history of postpartum depression of which $13.6 \%$ for VD and the remaining $6.2 \%$ for $\mathrm{CS}$. In addition to this, $36.4 \%$ of the respondents had a family history of depression of which $28.2 \%$ for VD and $8.1 \%$ for CS.

Prevalence of postpartum depression

The total proportion of depression among the study participants was $40(13 \%)$ of which $9.1 \%$ were VD and $3.9 \%$ were CS. Twenty-six (8.4\%) of the respondents scored 0 whereas only two $(0.6 \%)$ scored 28 with the cutoff point $>13$ and $40(13 \%)$ scored above the cutoff point (see figure 1).

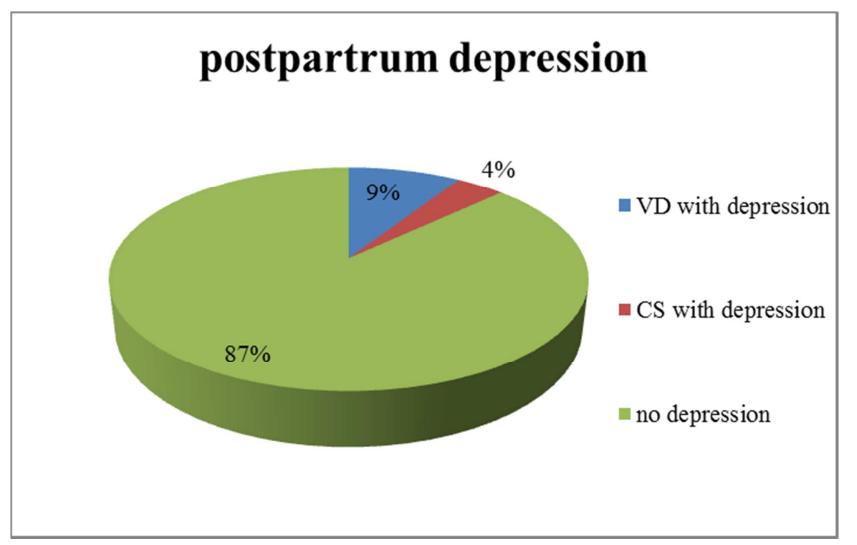

Figure 1. The proportion of postpartum depression among postpartum women of cesarean section as compared to vaginal delivery at Finoteselam hospital, North West Ethiopia, 2018 (n=308).

Edinburgh postnatal depression scale responses among participants

Edinburg postnatal depression scale composed often questions which indicate how the Mother has felt during the previous seven days. Questions 1, 2 and 4 were scored 0, 1, 2 and 3 whereas questions 3, 5-10 were scored 3, 2, 1 and 0 . Therefore, there was a recording of those question. From all the respondents only $1(0.3 \%)$ in CS. Seven $(2.3 \%)$ of the participants in vaginal delivery and $1(.3 \%)$ it was so difficult to look forward with enjoyment to things. Most of the time 4 
$(1.3 \%)$ in vaginal delivery and $6(1.9 \%)$ in the cesarean section were blaming themselves unnecessarily. Regarding scaring or panicking for no good reason $4(1.3 \%)$ for vaginal delivery and $2(0.6 \%)$ for a cesarean section of the participants reported that they faced it quite a lot. From all the respondents $18(5.9 \%)$ in vaginal delivery and $4(1.3 \%)$ stated that they couldn't be able to cope up with things at all. Most of the time for $4(1.3 \%)$ cesarean section of the study participants it was difficult to sleep. Seven $(2.3 \%)$ in vaginal delivery and $1(.3 \%)$ of respondents reported that most of the time they felt sad or miserable. In addition $4(1.3 \%)$ in vaginal delivery and $3(1 \%)$ in the cesarean section was unhappy and have been crying most of the time and only 4 $(1.3 \%)$ in vaginal delivery and $2(0.6 \%)$ in the cesarean section had thought of harming themselves (See table 2).

Table 2. Edinburgh Postnatal Depression scale of postpartum women at Finoteselam hospital, North West Ethiopia 2018 ( $n=308$ ).

\begin{tabular}{|c|c|c|c|c|}
\hline Characteristics & & Frequency (VD) & Frequency (CS) & Total delivery \\
\hline \multirow{4}{*}{$\begin{array}{l}\text { Experienced laugh and see } \\
\text { funny side of things }\end{array}$} & As much as always I could & $126(40.9 \%)$ & $31(101 \%)$ & $157(51 \%)$ \\
\hline & Not quite so much now & $88(28.6 \%)$ & $32(10.4 \%)$ & $120(39 \%)$ \\
\hline & Definitely not so much now & $24(7.8 \%)$ & $6(1.9 \%)$ & $30(9.7 \%)$ \\
\hline & Not at all & $0(0 \%)$ & $1(.3 \%)$ & $1(.3 \%)$ \\
\hline \multirow{3}{*}{$\begin{array}{l}\text { Look forward with enjoyment } \\
\text { to things }\end{array}$} & As much as I ever did & $145(47.1 \%)$ & $43(14 \%)$ & $188(61.1 \%)$ \\
\hline & Rather less than I used to & $65(21.1 \%)$ & $16(5.2 \%)$ & $81(26.3 \%)$ \\
\hline & Definitely less than I used to & $21(6.8 \%)$ & $10(3.2 \%)$ & $31(110 \%)$ \\
\hline \multirow{4}{*}{ Blamed yourself unnecessarily } & No never & $125(40.6 \%)$ & $33(10.7 \%)$ & $158(51.3 \%)$ \\
\hline & Not very often & $80(26 \%)$ & $13(4.2 \%)$ & $93(30.2 \%)$ \\
\hline & Yes some $f$ the time & $29(9.4 \%)$ & $18(5.8 \%)$ & $47(15.2 \%)$ \\
\hline & Yes most of the time & $4(1.3 \%)$ & $6(1.9 \%)$ & $10(3.2 \%)$ \\
\hline \multirow{3}{*}{$\begin{array}{l}\text { Been anxious or worried for no } \\
\text { good reason }\end{array}$} & No not at all & $151(49 \%)$ & $43(14 \%)$ & $194(63 \%)$ \\
\hline & Hardly ever & $57(18.5 \%)$ & $19(6.2 \%)$ & $76(24.7 \%)$ \\
\hline & Yes sometimes & $27(8.8 \%)$ & $7(2.3 \%)$ & $34(11.1 \%)$ \\
\hline \multirow{3}{*}{$\begin{array}{l}\text { Felt scared or panic for no good } \\
\text { reason }\end{array}$} & No, not much & $52(16.9 \%)$ & $21(6.8 \%)$ & $73(23.7 \%)$ \\
\hline & Yes, sometimes & $22(7.1 \%)$ & $9(2.9 \%)$ & $31(10 \%)$ \\
\hline & Yes, quite a lot & $4(1.3 \%)$ & $2(.6 \%)$ & $6(.1 .9 \%)$ \\
\hline \multirow{4}{*}{ Things have been on top of you } & No, I have been coping & $108(35.1 \%)$ & $28(9.1 \%)$ & $136(44.2 \%)$ \\
\hline & No most of the time & $77(25 \%)$ & $23(7.5 \%)$ & $100(32.5 \%)$ \\
\hline & Yes sometimes I haven't been coping as well as usual & $35(11.3 \%)$ & $15(4.9 \%)$ & $50(16.2 \%)$ \\
\hline & Yes most of the time I haven't been able to cope at all & $18(5.9 \%)$ & $4(1.3 \%)$ & $22(7.2 \%)$ \\
\hline \multirow{4}{*}{ Difficult to sleep } & No, not at all & $118(38.3 \%)$ & $28(9.1 \%)$ & $146(47.4 \%)$ \\
\hline & Not, very often & $80(25.9 \%)$ & $28(9.1 \%)$ & $108(35 \%)$ \\
\hline & Yes sometimes & $36(11.7 \%)$ & $10(3.2 \%)$ & $46(14.9 \%)$ \\
\hline & Yes most of the time & $0(0 \%)$ & $4(1.3 \%)$ & $4(1.3 \%)$ \\
\hline \multirow{4}{*}{ Felt sad or miserable } & No, not at all & $118(38.3 \%)$ & $29(9.4 \%)$ & $147(47.7 \%)$ \\
\hline & Not, very often & $66(21.5 \%)$ & $18(5.8 \%)$ & $84(27.3 \%)$ \\
\hline & Yes, quite often & $47(15.2 \%)$ & $22(7.1 \%)$ & $69(22.3 \%)$ \\
\hline & Yes, most of the time & $7(2.3 \%)$ & $1(.3 \%)$ & $8(2.6 \%)$ \\
\hline \multirow{2}{*}{$\begin{array}{l}\text { So unhappy you have been } \\
\text { crying }\end{array}$} & Yes quite often & $10(3.3 \%)$ & $7(2.3 \%)$ & $17(5.6 \%)$ \\
\hline & Yes, most of the time & $4(1.3 \%)$ & $3(1 \%)$ & $7(2.6 \%)$ \\
\hline \multirow{4}{*}{ Thought of harming your self } & Never & $199(64.6 \%)$ & $55(17.9 \%)$ & $254(82.5 \%)$ \\
\hline & Hardly ever & $17(5.5 \%)$ & $5(1.6 \%)$ & $22(7.1 \%)$ \\
\hline & Sometimes & $18(5.9 \%)$ & $8(2.6)$ & $26(8.5 \%)$ \\
\hline & Yes, quite often & $4(1.3 \%)$ & $2(.6 \%)$ & $6(2.3 \%)$ \\
\hline
\end{tabular}

Bivariate and multivariate logistic regression analysis of postpartum depression and its associated factors

Binary logistic regression was performed to assess the association of each Independent variable with the outcome variable of postpartum depression. The variables that showed a significant level $(\mathrm{p}<0.2)$ were added to the multivariate regression model. Hence, only seven variables were found to have a significant association with postpartum depression. The result revealed that study subjects by educational status who were secondary school were associated with the dependent variable by having 8.818 odds of post-partum depression when compared with those who were primary school $[$ AOR $=8.818$ (1.596-48.716)].

In addition, respondents who had husband support were nearly $4.8 \%$ less likely to be depressed than those who had no husband support [.048 (.014-.164)]. The other variable that was found to have an association was a participant's previous history of abortion. Respondents who had experienced abortion at least twice were $16 \%$ less likely to be depressed than others $[\mathrm{AOR}=.160(.034-.746)]$. Furthermore, any negative life event was also found affecting the outcome variable. Those women who had any negative life event were over 17 times more likely to have postpartum depression compared to those who had no any negative life event 
[AOR=17.322 (4.753-63.135)].

Those women who had no family history of mental illness have $18.7 \%$ less likely risk than who have near family history of postpartum depression [AOR $=0.187(.053-659)]$.

Respondents who had a previous history of depression were almost 6 times more likely to be depressed as compared to women who had no history of depression $[\mathrm{AOR}=5.498$
(1.843-16.405)]. Respondents who had not faced with domestic violence were $25 \%$ less likely risk to verbal report postpartum depression. $[\mathrm{AOR}=.250 \quad(.065-.956)]$. Respondents who had 2 previous abortion history were less likely to be depressed than their counterparts $[\mathrm{AOR}=0.160$ (0.034-0.746) (Table 3).

Table 3. Bivariate and Multivariate analysis of post-partum women grossly at Finoteslam Hospital North West Ethiopia, 2018 ( $n=308$ ).

\begin{tabular}{|c|c|c|c|c|c|}
\hline \multirow{2}{*}{ Variables } & & \multicolumn{2}{|c|}{ Postpartum Depression } & \multirow{2}{*}{ COR (95\% C. I) } & \multirow{2}{*}{$\operatorname{AOR}(95 \% \mathrm{CI})$} \\
\hline & & Yes & no & & \\
\hline \multirow{6}{*}{$\begin{array}{l}\text { Level of } \\
\text { educational status }\end{array}$} & Primary school & $7(2.3 \%)$ & $52(16.9 \%)$ & 1 & 1 \\
\hline & Secondary school & $13(4.2 \%)$ & $33(10.7 \%)$ & $2.926(1.058-8.092)^{*}$ & $8.818(1.596-48.716)^{* *}$ \\
\hline & Technical & $0 \%$ & $14(4.5 \%)$ & .000 & .000 \\
\hline & Diploma & $3(1 \%)$ & $16(5.2 \%)$ & $1.393(.32-6.021)$ & $1.231(.106-14.252)$ \\
\hline & Firs degree and above & $1(.3 \%)$ & $26(8.4 \%)$ & $.286(.033-1.44)$ & $.640(.035-11.789)$ \\
\hline & Illiterate & $16(5.2 \%)$ & $127(41 . \%)$ & $.936(.364-2.408)$ & $1.353(.294-6.215)$ \\
\hline \multirow{3}{*}{ Husband support } & Yes & $10(3.2 \%)$ & $233(75.6 \%)$ & $.050(.023-.111)^{*}$ & $.048(.014-.164)^{* *}$ \\
\hline & No & $30(9.7 \%)$ & $35(11.4 \%)$ & 1 & 1 \\
\hline & 1 & $6(1.9 \%)$ & $64(20.8 \%)$ & 1 & 1 \\
\hline \multirow{3}{*}{ Abortion } & 2 & $4(1.3 \%)$ & $19(6.2 \%)$ & $.639(.252-1.618)$ & $.160(.034-.746)^{* *}$ \\
\hline & 3 & $2(.6 \%)$ & $1(.3 \%)$ & $1.435(.454-4.537)$ & $1.844(.291-11.707)$ \\
\hline & 4 & $1(.3 \%)$ & $0 \%$ & $13.635(1.195-155.469)^{*}$ & $2.44(.104-57.44)$ \\
\hline History of & Yes & $(7.523 \%)$ & $38(12.3 \%)$ & $8.189(4.007-16.734)^{*}$ & $5.498(1.843-16.405)^{* *}$ \\
\hline \multirow[t]{2}{*}{ Depression } & NO & $17(5.5 \%)$ & $230(74 \%)$ & 1 & 1 \\
\hline & verbal & $14(4.5 \%)$ & $24(7.8 \%)$ & 1 & 1 \\
\hline \multirow{3}{*}{ Domestic violence } & Physical & $2(.6 \%)$ & $8(2.6 \%)$ & $7.00(3.096-15.828)^{*}$ & $.079(.005-1.370)$ \\
\hline & Both & $6(1.9 \%)$ & $20(6.5 \%)$ & $3.00(.592-15.195)$ & $.095(.014-.657)$ \\
\hline & no violence & $18(5.8 \%)$ & $116(70 \%)$ & $3.600(1.284-10.097)^{*}$ & $.250(.065-.956)^{* *}$ \\
\hline \multirow{2}{*}{ Negative life event } & Yes & $20(6.5 \%)$ & $39(12.7)$ & $5.872(2.986-11.904)^{*}$ & $17.322(4.753-63.135) * *$ \\
\hline & No & $20(6.5 \%)$ & $229(74 \%)$ & 1 & 1 \\
\hline \multirow{3}{*}{ mental illness } & near relative & $15(4.9 \%)$ & $50(16.2 \%)$ & 1 & 1 \\
\hline & distant relative & $10(3.2 \%)$ & $37(12 \%)$ & $.901(.364-2.229)$ & $.533(.118-2.408)$ \\
\hline & No & $15(4.9 \%)$ & $181(58.8 \%)$ & $276(.126-.603)^{*}$ & $.187(.053-0.659)^{* *}$ \\
\hline
\end{tabular}

$*=$ p-value $<0.2$.

$* *=\mathrm{p}$-value $\leq 0.05$

\section{Discussion}

The present study showed that the proportion of postpartum depression for normal vaginal deliveries was higher than a cesarean section. Our finding revealed that the mode of delivery was not found to be associated with our postpartum depression. This finding is in line with the studies conducted at Turkey and Iran about the mode of delivery and postpartum depression [26, 27]. On the contrary to the finding of our research studies conducted in different countries revealed that respondents underwent to the cesarean section was found to be with postpartum depression than normal vaginal delivery $[20,28,29]$. This might be due to a link with the respondents' frustration about the surgical procedure which may influence their mental situation and the impact of different anesthetics on the human physiology.

This study was somewhat comparable with the other studies conducted in London (10\%), at Kenyatta Hospital in Kenya $(10.6 \%)$ and in Sudan $(9.2 \%)[13,15,16]$. The possible explanation for this may be due to methodological and assessment tool similarities of the studies. The finding of this study was lower than the local studies conducted at Addis Ababa (23.3\%) and Northeastern Tigray 24\% [12, 17]. This might be due to the usage of larger sample size, the smaller cutoff point of the PPD scale and time of the study differences.

The result of this study was lower than proportion of PPD of different studies conducted at India $(\mathrm{VD}=8.23 \%$, $\mathrm{CS}=21.7 \%$ ), Turkey ( $\mathrm{VD}=27.6, \quad \mathrm{CS}=31.8 \%$ and $34.9 \%$ respectively for both elective and emergency) and Iran $(\mathrm{VD}=18.3 \%$ and $\mathrm{CS}=25 \%)[20,26,27)]$. The possible reason for this discrepancy might be due to the presence of smaller cutoff point and the time of the study conducted which the current study has been conducted at a time of humans life improved and special concern has given for health.

The highest proportion of patients belonged to 25- 34 years age groups in both the study groups of vaginal and Caesarean delivery which was $40.9 \%$ and $10.1 \%$ ) respectively. The result of this study was consistent with the proportion of patients from $20-30$ years of age which was high in both the study groups of vaginal delivery and cesarean section [14]. This might be due to younger women being more exposed to emotional distress as they experience childbirth for the first time and the extra burden was added for caring infants as well as the whole family in this particular period.

Another study done in India showed the postpartum depression was $21.17 \%$ in the cesarean section which was 
higher than the result of this study and nearly similar for vaginal deliveries which were $8.23 \%$ [20].

This study found that postpartum depression was significantly lower among women who have no self and family history of previous mental illness from their reference group. This result was consistent with a study conducted in Brazil [21]. This is maybe due to the fact that stress is one of the possible factors depressions. Participants who had previous depression had an association with PPD compared to those who had not the previous history of depression was in line with the findings of the study conducted in Addis Ababa [12] and Tigray [17]. This might be due to relapse of depression among women who had experienced mental health problem before was that they might stress themselves thinking about their pregnancy and delivery and as well as hormonal imbalance during pregnancy could also be the other reason for relapsing of depression.

Another finding in this study was the level of education in which participants prevalence of postpartum depression significantly higher among secondary school than their respective primary school. This result was consistent with a study conducted in Qatar assumes women who are educated are more risky for the problem [23]. The possible explanation, for this reason, maybe the more level of education increases the more students are eager for their lesson and they become depressed when they stop learning because of pregnancy faced. On the contrary, a case-control study in Cameron revealed that no socio-demographic variable was found to be a risk factor for postpartum depression [19].

In this study, the presence of husband support during childbirth was associated with postpartum depression. This result was consistent with a study conducted in Addis Ababa and Cameroon [12, 19]. Lack of support, love, affection, and guidance of the husband on top of a stressful childbirth event could make women vulnerable to postpartum depression.

Another variable associated with postpartum depression in the current study is the presence of domestic violence. The finding is consistent with the result of a study conducted in Addis Ababa, Pakistan and China showed domestic violence was the main factor for postpartum depression [12, 18, 24]. The possible reason for this might be violence of any kind has a devastating physical, psychological, behavioral and developmental effect on the victims.

The finding of this study showed a significant association between postpartum depression and women having a negative life event. This is similar to the finding of the study obtained from India and at Goba and Robe town [20, 22]. Abortion was also associated with higher odds of having postpartum depressions. This study is comparable with the study done in Cameroon [19]. This might be due to the fact that a negative life event in the previous history is most influential on an individual's mental status which might frighten from losing their newborn as well as their life.

\section{Conclusion}

Generally, the proportion of postpartum depression for vaginal deliveries was higher than cesarean deliveries. The highest proportion of respondents belonged to 25-34 years old in both the study groups of vaginal and Caesarean deliveries. The proportion of PPD among postpartum women was 9\% for vaginal deliveries and $4 \%$ was for cesarean section. Among the predictors; the previous history of postpartum depression, domestic violence, previous abortion history, women who faced negative event, previous history mental illness, level of education and husband support during pregnancy had an association with postpartum depression. Women's affair office should create Intersector collaboration with health institutions for those women who had a report of domestic violence and encourage women for education. Religious institutions, society leaders and parents should increase perception on the impact of no husband support for women among society.

\author{
Abbreviations
AOR $=$ Adjusted Odd Ratio
$\mathrm{COR}=$ Crude Odd Ratio
$\mathrm{CS}=$ Cesarean Section
$\mathrm{PPD}=$ Postpartum Depression
$\mathrm{VD}=$ Vaginal Delivery

\section{Authors' Contributions}

MM had involved in the conception, design, and analysis. NA had involved in interpretation and manuscript writing. Both authors read and approved the final manuscript.

\section{Authors' Information}

Mezgebu Mihret Kefale, Selamawit Lake Fenta and Fentahun Yenealem Beyene are lecturers in the Department of Midwifery College of Health Science and Medicine, Bahirdar University, Bahirdar, Ethiopia.

Natnael Atnafu Gebeyeheu is a lecturer in the Department of Midwifery, College of Health Science and Medicine, Wolaita Sodo University, Wolaita Sodo, Ethiopia

\section{Ethical Consideration}

Ethical clearance was obtained from the ethical Institutional Review Board (IRB) of Bahirdar University College of Medicine and Health Science. Letter of the permission was obtained from the Amhara regional public health institution. All the study participants had been informed about the purpose of the study, their right to refuse and assurance of confidentiality. Oral informed consent was obtained from every respondent.

\section{Limitation of the Study}

The study was limited to 6 weeks postpartum; the presence of depression beyond those weeks of postnatal months was not investigated.

Edinburgh postnatal depression scale is a screening tool, 
not a diagnostic tool to assess the presence of depression.

Because of stigma towards mental illness, the respondents might not report what they feel this would decrease the prevalence of postpartum depression.

\section{Consent for Publication}

Not applicable.

\section{Availability of Data and Materials}

The data that support the findings of this study are available but some restrictions may apply to the availability of these data as there are some sensitive issues. However, data are available from the corresponding authors upon reasonable request.

\section{Competing Interests}

The authors declare that they have no competing interests.

\section{Funding}

Bahirdar University.

\section{Acknowledgements}

We would like to express our deepest heartfelt thanks to Bahirdar University for allowing us to conduct the study. Our special thanks go to Finoteselam Hospital management and health provider staffs for their invaluable assistance throughout the study.

\section{References}

[1] Haudron, L. H. Postpartum Depression. Pediatrics in review, 2003. 24 (5): p. 155.

[2] World Health Organization. (2005). Atlas: child and adolescent mental health resources: global concerns: implications for the future. World Health Organization. https://apps.who.int/iris/handle/10665/43307.

[3] Azale, T. A. Fekadu, and C. Hanlon, Treatment gap and helpseeking for postpartum depression in a rural African setting. BMC Psychiatry, 2016. 16 (1): p. 196.

[4] Braveman, P., et al., Poverty, near-poverty, and hardship around the time of pregnancy. Maternal and Child Health Journal, 2010. 14 (1): 20-35.

[5] Yelland, J., G. Sutherland, and S. J. Brown, Postpartum anxiety, depression and social health: findings from a population-based survey of Australian women. BMC Public Health. 2010 Dec 20; 10: 771

[6] Milgrom J GA, B. J., et al, Antenatal risk factors for postnatal depression: a large Prospective study. J Affect Disord. 2008. 108 (1-2): 147-57.

[7] WHO. World Health Statistics 2010: WHO Statistical Information System (WHOSIS).
[8] Burns, D. Aspects of Postpartum Depression. London, Ontario: December 2003.

[9] Epperson, C. Postpartum major depression: Detection and treatment; American Family Physician., (2016). 59, 22472254.

[10] Nonacs, R., \& Cohen. Postpartum mood disorders: diagnosis and treatment guidelines. Journal of Clinical Psychiatry, (2004). 59, S. 2, 34-40

[11] Lanes, A., J. L. Kuk, and H. Tamim. Prevalence and characteristics of postpartum depression symptomatology among Canadian women: a cross-sectional study. BMC public health, 2011.11 (1): p. 302.

[12] Addishiwet Fantahun, Amsale Cherie, and Leul Deribe. Prevalence and Factors Associated with Postpartum Depression Among Mothers Attending Public Health Centers of Addis Ababa, Ethiopia: Clin Pract Epidemiol Ment Health. 2018; 14: 196-206.

[13] The British Psychological Society \& The Royal College of Psychiatrists. Antenatal and Postnatal Mental Health: The NICE Guideline on Clinical Management and Service Guidance: National Collaborating Centre for Mental Health (UK); 2007.

[14] Dinesh P, Swetha Raghavan. A comparative study of the prevalence of postnatal depression among subjects with normal and cesarean deliveries. IAIM, 2018. 5 (2): 6-11.

[15] Virginia Mwikali Musau. The prevalence of postpartum depression among women delivering at Kenyatta national hospital. Department of Obstetrics and Gynecology University of Nairobi. 2013 (unpublished work).

[16] Khalifa DS, Glavin K, Bjertness E, Lien L. Postnatal depression among Sudanese women: prevalence and Validation of the Edinburgh Postnatal Depression scale at 3 months postpartum: Int J Womens Health. 2015 Jul 8; 7: 67784.

[17] Deribachew H/Mariam, Berhe Dessalegn, Zaid Tadesse and Desta Siyoum. Assessment of prevalence and associated factors of postpartum depression among postpartum mothers in the eastern zone of Tigray. 2016. European Journal Of Pharmaceutical And Medical Research; 2016, 3 (10), 54-60.

[18] Niloufer S Ali B, I. S. A., Postpartum anxiety and depression in peri-urban communities of Karachi, Pakistan: a quasi-experimental study. BMC Public Health, 2009. 9: 384 .

[19] Nadège Djoda, Pascal Foumane, Jean Pierre Kamga Olen, et al. Prevalence and Risk Factors of Postpartum Depression in Yaounde, Cameroon: Open Journal of Obstetrics and Gynecology; 2015, 5, 608-617.

[20] Mahishale A, B. J., Comparison of the level of depression among mothers with lower segment cesarean section and vaginal delivery: A cross-sectional study. Journal of the Scientific Society, 2017; 44 (1): 15-9. 13.

[21] Amaury Cantilino, Carla Fonseca Zambaldi, Thiago Lucena César de Albuquerque, et. al. Postpartum depression in Recife-Brazil: prevalence and Association with bio-socio-demographic factors: artigo original; 2010; 59 (1): (1-9). 
[22] Tomas Benti Tefera, Asfaw Negero Erena, Kemal Ahmed Kuti, and Mohammedawel Abduku Hussen. Perinatal depression and associated factors among reproductive-aged Group women at Goba and Robe Town of Bale Zone, Oromia Region, South East Ethiopia; Matern Health Neonatol Perinatol. 2015; 1: 12 .

[23] Bener A, Gerber LM, Sheikh J. Prevalence of psychiatric disorders and associated risk factors in women during their postpartum period: a major public health problem and global comparison. International Journal of Women's Health, 2012. 4 (191-200).

[24] Zhang Y, Zou S, Cao Y, Zhang Y. Relationship between domestic violence and postnatal depression among pregnant Chinese women: nt J Gynaecol Obstet. 2012 Jan; 116 (1): 2630 .

[25] Cox J, Holden JM, Sagovsky R. Detection of postnatal depression: Development of the 10-item Edinburgh Postnatal Depression Scale. Br J Psychiatry 1987; 150: 782-6.

[26] Asli Goker, Emre Yanikkerem, Murat Demet, et. al. Postpartum Depression: Is mode of delivery a risk factor? International scholar research network Obstetrics and Gynecology: Volume 2012, Article ID 616759, 6.

[27] Mohammad Arbabi, Ziba Taghizadeh, Sedigheh Hantoushzadeh and Edith Haghnazarian. Mode of delivery and postpartum depression: J Women's Health Care 2016, 5: 1.

[28] Malik PR, Malik BB, Irfam. Comparison of postnatal depression in women following normal vaginal deliveries and cesarean section. Journal of post-grad Med Inst 2015, 29 (1): 34-7.

[29] Guler Ateşer, İsa Şukru Oz, Sevinj Sardarli, et, al. Has delivery method any influence on the postpartum mood of the mother? Istanbul MedJ 2017; 18: 62-7. 